\title{
Kinetic Analysis of Human Sitting in Front of Computer for Developing Compensatory Exercises
}

\author{
Dr. Mohamed GaberBreka \\ Dr. Ibrahim Farouk Gabr ${ }^{2}$ Dr. NourhanSoliman Hassan ${ }^{3}$
}

Abstract:The current research aims to achieve muscular balance during sitting in front of computers through anatomical analysis of sitting position in front of computers, EMG analysis of working muscles during sitting position in front of computers and designing a compensatory exercises program for sitting position in front of computers. The researchers used the descriptive (qualitative anatomical analysis of sitting position in front of computer - quantitative EMG analysis) approach. Only one participant was purposefully chosen. She was a female employee whose work required sitting for prolonged periods of time in front of a computer (age: 23 years - height: $169 \mathrm{~cm}$ - weight: $75 \mathrm{~kg}$ ). The researchers chose to perform research analyses in Kinematic Analyses Lab of Biomechanics Department - Faculty of Physical Therapy - Cairo University.

1- Descriptions of various sitting positions in front of computer are as follows:

- Muscle groups with highest contraction during Lie Back $135^{\circ}$ are: pectorals major - rectus abdomens - erector spinae - latissimus dorsi - deltoid .

- Muscle groups with highest contraction during Upright $90^{\circ}$ are: rectus abdomens pectorals major - rectus femoris - erector spinae - latissimus dorsi .

- Muscle groups with highest contraction during Lean Forward $70^{\circ}$ are: rectus abdomens pectorals major - rectus femoris - latissimus dorsi - deltoid.

2- Descriptions of various sitting positions in front of computer according to EMG for contribution percentages are as follows.

- Lie Back 135: highest contribution for trunk movers.

- Upright 90: least percentage of contractions for all muscle groups .

- Lean Forward 70: highest contribution for pectorals major - rectus abdomens.

3- There is no best position for sitting as the body should not stay on one position for too long.

4- Fixed positions cause negative effects on the spine and its working muscles

5- Compensatory exercises are designed.

Key words: kinetic analysis - human posture - compensatory exercises

\section{Background and Research Problem:}

Ergonomics is a new field of study that requires data about human performance in addition to knowledge about factors affecting workplaces. Its objective is to save time through making workplace and equipment safer, more effective, more comfortable and more easy-to-use for those who work in this place.

Body position during work and its fitness to do certain tasks provide us with full data to be used in analyzing time of beginning work to calculate energy expenditure during work in

\footnotetext{
${ }^{1}$ Professor of Biomechanics-Sports Training and Kinesiology Department-Faculty of Physical Education - Tanta University

${ }^{2}$ Assistant Professor - Sports Training and Kinesiology Department - Faculty of Physical Education - Tanta University

${ }^{3}$ Sports Specialist - Alexandria University
} 
addition to required time for production and rest intervals during and after work hours. This prevents injuries resulting from overuse of a certain tool for prolonged periods of time.

Applications of kinesiology for human health include biomechanics, bone strength, adaptation and rehab, physical and occupational therapy and above all sports involvement. Human motion studies include motion detection systems, EMG, EEG in addition to other methods for measuring physiological functions of working muscles and other cognitive and behavioral research techniques (Algammal 2007) (1) (Dawn 2013) (9).

Most young people and governmental employees are required to sit on their disks for prolonged periods of time in addition to their persistence on using smart phones, computer devices, laptops and I-pads in unbelievable rates. They are overwhelmed by modern technology in a way that made them lose their abilities to practice sport. Modern technology has turned most people into "sitting" people as the sitting position became the dominating position among humans. This particular position is the main cause for cervical and lumbar pain. In addition, it leads to shortening front muscles and narrowing chest muscles. This leads to heavy breathing. (Briggs et al 2009) (2), (Scott 2013) (14) (Steven et al 2013) (7)

Compensatory exercises have specific objectives of restoring muscular balance and repairing abnormalities in it. Practicing these exercises guarantees good performance of sports exercises according to systematic steps to compensate any specific motor limitation. It is called equilibrium exercises as it cannot be ignored for preventing functional disorders in the musculature. Its major use is in cases of overloads on certain parts of the musculature due to incorrect motion patterns in addition to prolonged periods of static activities (Matthew Wyon 2014) (8).

According to review of literature related to biomechanical (quantitative and qualitative) analysis and EMG of sitting position in front of computer, the researchers noticed that no previous Arabic studies were performed to deal with this issue. Furthermore, some foreign studies like Burnett et al (2008) (4) compared optimal and normal sitting positions, while Claus et al (2009) (6) analyzed positions of spinal cord and levels of EMG and Mabb et al (2013) (7) analyzed optimal sitting positions of youth, symptoms of EMG and curves of the backbone. But no study investigated athletes or training programs as potential solution for this global problem. The researchers found that it is necessary to perform the current research as a realistic vision of the future role of sport to face the hazards of technology on our life and health in general and especially the health of Arab youth in the future in all fields including sport and sports training. It is a step towards identifying the role of sport in solving problems of the society and establishing its clear and important role in serving social issues in addition to expanding the base of involvement for sports activities.

The researchers are trying to put some recommendations concerning a compensatory exercises program to achieve muscular balance the sitting in front of computers position in addition to treating functional disorders resulting from this position through the results of a qualitative anatomical analysis, EMG analysis and percentages of involvement of working muscles according to its various roles in this position. In addition, the researchers are trying to identify quantitative and qualitative criteria of the recommended compensatory exercises program. 
Aim:

The current research aims to achieve muscular balance during sitting in front of computers through:

1. Anatomical analysis of sitting position in front of computers

2. EMG analysis of working muscles during sitting position in front of computers

3. Designing a compensatory exercises program for sitting position in front of computers

\section{Research Questions:}

1. What is the anatomical analysis of sitting positions in front of computers?

2. What are the percentages of contribution for working muscles during sitting positions in front of computers?

3. What is the recommended compensatory exercises program?

\section{Methods:}

\section{Approach:}

The researchers used the descriptive (qualitative anatomical analysis of sitting position in front of computer - quantitative EMG analysis) approach.

\section{Participant:}

Only one participant was purposefully chosen. She was a female employee whose work required sitting for prolonged periods of time in front of a computer (age: 23 years - height: 169 $\mathrm{cm}$ - weight: $75 \mathrm{~kg}$ ).

\section{Geographic Field:}

The researchers chose to perform research analyses in Kinematic Analyses Lab of Biomechanics Department - Faculty of Physical Therapy - Cairo University.

\section{Data Collection Tools:}

- Related literature (books - studies - websites)

- Interviews with employees of computer labs and units to identify the problem and its potential solutions

- Qualitative anatomical analysis of sitting position in front of computer through images of sitting position angles to identify the most important active muscle groups, types of muscle contraction, moments of angular acceleration of joints, places of effect and any excessive increase of the joint range of motion during sitting position in front of the computer.

- Identification of prime movers for biomechanical EMG analysis

- Anthropometric measurements:

- A graded tape for measuring height to the nearest $0.05 \mathrm{~cm}$

- A medical balance for measuring weights to the nearest $0.05 \mathrm{~kg}$

- EMG devices:

- Pro-reflex 120Hz/sec cameras (6)

- Surface electrodes (4) 
- Junction box 500:20000 Hz

- EMG Biopac System - M. P. 100

- HP computer unit

- Control board

- Printer

\section{Main Study:}

To fulfill the research objectives, the researchers followed several steps as follows in performing anatomical analysis according to Brekaa\&Elsokary (2010) (3)

1. Dividing skills into periods of time and basic stages

2. Identifying joints, movements, motion directions (or ranges) and freedom degrees

3. Identifying the types of muscle contraction and major muscle groups involved in motion

4. Identifying moments of angular acceleration for joints (increase/decrease of joint movement) and places of effect

5. Identifying any excessive increase in joints' ranges of motion

Sitting positions are divided into three stages:

1. Lie back $\left(135^{\circ}\right)$

2. Upright $\left(90^{\circ}\right)$

3. Lean forward $\left(70^{\circ}\right)$

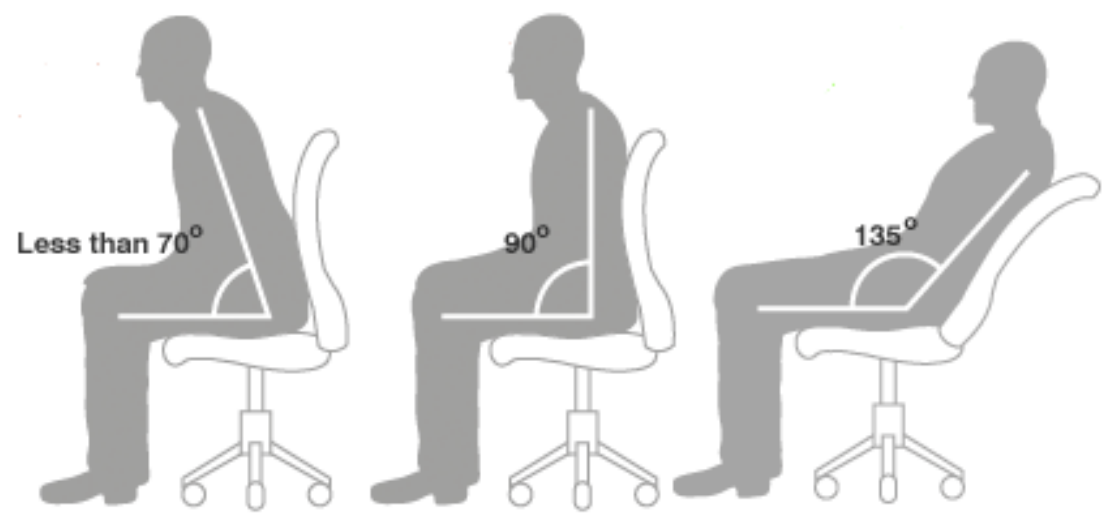

Fig (1): angles used in quantitative and qualitative analyses of sitting positions

(Burnett et al 2008) (4) (Claus et al 2009) (6) (Mabb et al 2013) (7) 


\section{Results:}

Table (1): Qualitative Anatomical Analysis of Sitting Positions under Investigation

\begin{tabular}{|c|c|c|c|c|c|c|c|c|c|}
\hline Joint & Joint motion & $\begin{array}{c}\text { Moving } \\
\text { link }\end{array}$ & Level & Axis & Contraction & $\begin{array}{l}\text { Active } \\
\text { muscle } \\
\text { groups }\end{array}$ & Working muscles & $\begin{array}{l}\text { Angular } \\
\text { acceleration }\end{array}$ & $\begin{array}{c}\text { Excessive } \\
\text { increase in range } \\
\text { of motion }\end{array}$ \\
\hline $\begin{array}{l}\text { Trunk } \\
\left(135^{\circ}\right)\end{array}$ & Extension & $\begin{array}{l}\text { Spine } \\
\text { pelvic }\end{array}$ & Horizontal & Vertical & Eccentric & \begin{tabular}{|l|} 
Chest \\
extensors \\
Low back \\
extensors
\end{tabular} & $\begin{array}{l}\text { Pectoralis major and } \\
\text { minor } \\
\text { Serratus anterior } \\
\text { External intercostal }\end{array}$ & Non & Non \\
\hline $\begin{array}{l}\text { Trunk } \\
\left(90^{\circ}\right)\end{array}$ & Fix & Spine & Horizontal & Vertical & Isometric & $\begin{array}{l}\text { Lift/right } \\
\text { rotators }\end{array}$ & \begin{tabular}{|l|} 
Internal oblique \\
External oblique \\
Erector spinae \\
\end{tabular} & With & - \\
\hline \begin{tabular}{|l} 
Trunk \\
$\left(70^{\circ}\right)$
\end{tabular} & Contraction & $\begin{array}{l}\text { Spine } \\
\text { pelvic }\end{array}$ & Horizontal & Vertical & Eccentric & \begin{tabular}{|lr}
\multicolumn{2}{|l|}{ Chest flexors } \\
Low back \\
flexors
\end{tabular} & $\begin{array}{l}\text { Pectoralis major and } \\
\text { minor } \\
\text { Serratus anterior } \\
\text { External intercostal } \\
\text { Latissimus dorsi } \\
\end{array}$ & & \\
\hline $\begin{array}{l}\text { Thigh } \\
\left(135^{\circ}\right)\end{array}$ & $\begin{array}{l}\text { Extension of } \\
\text { joint }\end{array}$ & Pelvic & Side & Horizontal & Eccentric & \begin{tabular}{|l|} 
External \\
flexors \\
rotators
\end{tabular} & $\begin{array}{l}\text { Triceps femoris } \\
\text { Rectus femoris } \\
\text { Maximus gluteus } \\
\text { Gluteus medialis } \\
\end{array}$ & - & - \\
\hline $\begin{array}{l}\text { Thigh } \\
\left(90^{\circ}\right)\end{array}$ & Fix & & Side & Horizontal & Isometric & \begin{tabular}{|l|} 
External \\
flexors \\
rotators
\end{tabular} & \begin{tabular}{|l} 
Lower sacral \\
Maximus gluteus \\
Gluteus medialis \\
Quadriceps \\
Rectus femoris \\
Vastuslateralis \\
Vastusmedialis \\
Vastus internal
\end{tabular} & & \\
\hline $\begin{array}{l}\text { Thigh } \\
\left(70^{\circ}\right)\end{array}$ & $\begin{array}{l}\text { Contraction } \\
\text { external } \\
\text { rotation }\end{array}$ & & Side & Horizontal & Eccentric & \begin{tabular}{|l|} 
External \\
flexors \\
rotators
\end{tabular} & \begin{tabular}{|l} 
Gracilis \\
Rectus femoris \\
Sartorius \\
Adductor magnus \\
Adductor longos \\
Gluteus medialis \\
gluteus Maximus \\
Gluteus minor \\
Tensor fascia latae + \\
+ iliac
\end{tabular} & & \\
\hline Knee & \begin{tabular}{|l} 
Extension \\
contraction
\end{tabular} & $\begin{array}{l}\text { Leg } \\
\text { thigh }\end{array}$ & $\begin{array}{l}\text { Side } \\
\text { side }\end{array}$ & $\begin{array}{l}\text { Horizontal } \\
\text { Horizontal }\end{array}$ & $\begin{array}{l}\text { Concentric } \\
\text { Eccentric }\end{array}$ & $\begin{array}{l}\text { Extensors }+ \\
\text { extensors }\end{array}$ & $\begin{array}{l}\text { Quadriceps } \\
\text { Rectus femoris } \\
\text { Vastuslateralis } \\
\text { Vastus internal } \\
\text { Vastusmedialis } \\
\text { Vastuslateralis } \\
\text { Vastus internal } \\
\text { Vastusmedialis }\end{array}$ & - & - \\
\hline
\end{tabular}

Table (2): Percentages of EMG Involvement for Some Major Muscles According to its Role in Positions of Sitting

\begin{tabular}{|c|c|c|c|c|c|c|c|c|}
\hline Muscles & $\begin{array}{c}\text { Rectus } \\
\text { femoris }\end{array}$ & Abdomens & $\begin{array}{c}\text { Erector } \\
\text { spinae }\end{array}$ & Gastrocnemius & $\begin{array}{c}\text { Sacro } \\
\text { spinalis }\end{array}$ & $\begin{array}{c}\text { Latissimus } \\
\text { dorsi }\end{array}$ & Semimembranosus & $\begin{array}{c}\text { Pictorials } \\
\text { major }\end{array}$ \\
\hline angle (135)Stage & $3 \%$ & $6 \%$ & $5 \%$ & $1.5 \%$ & $3 \%$ & $4 \%$ & $2 \%$ & $6 \%$ \\
\hline angle (90)Stage & $6 \%$ & $4 \%$ & $5 \%$ & $5 \%$ & $1 \%$ & $4 \%$ & $2 \%$ & $4 \%$ \\
\hline angle (70)Stage & $7 \%$ & $8 \%$ & $2 \%$ & $2 \%$ & $2 \%$ & $6 \%$ & $4 \%$ & $8 \%$ \\
\hline
\end{tabular}




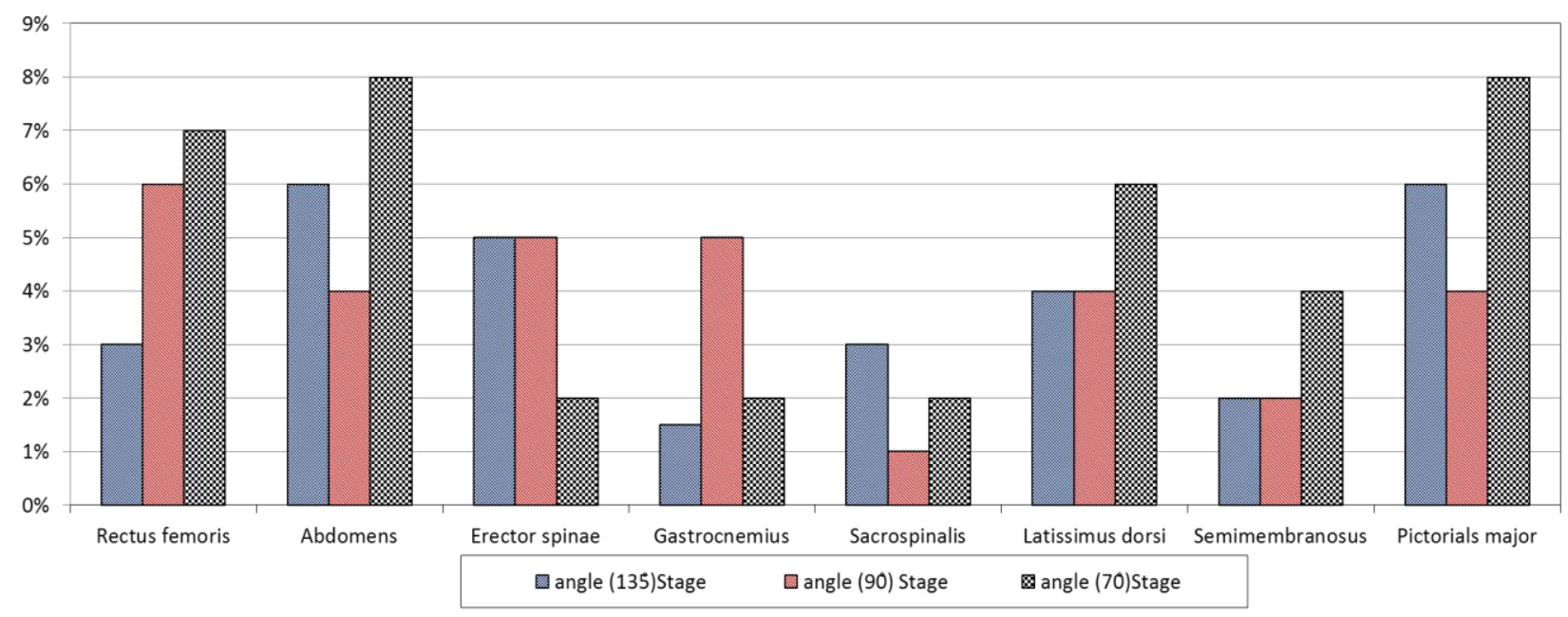

Fig (2): Contribution percentages of some active muscle groups during sitting positions

\section{Discussion:}

First: Results of Qualitative Anatomical Analysis during Sitting:

From table (2) it is clear that:

\section{Trunk Positions:}

At the beginning of "Lie Back 135", pelvic and backbone motions are directed sideways on the horizontal axis through eccentric muscle work on counter direction of force as a negative work for chest extensors (pectorals major - pectorals minor - external intercostal) and low back flexors (oblique - Latissimus dorsi - rhomboid major - rhomboid minor).

As for "Upright $90^{\circ}$ ", it is a stage of fixing the backbone sideways on a horizontal axis through isometric work of right/lift rotators towards the key board or the mouse or the screen. Work direction was "positive" for the following muscles: gluteus medius + external/internal oblique - erector spinae - sacrospinalis - deep back group - sternocleidomastoid.

As for "Lean Forward $70^{\circ}$ ", this is the maximum muscle contraction through eccentric muscle work on counter direction of force (negative work) for: pectorals major - serratus posterior (high / low) - rectus abdomens - oblique (external / internal) - inguinal - iliac crest lumbar extrusion. Muscles working on lumbar vertebrae are extended through eccentric work of: pectorals major - serratus anterior - external intercostal - Latissimus dorsi.

\section{Thigh Joint:}

As for "Lie Back 135", joint extension and external rotation is clear on horizontal level and vertical axis through eccentric work on counter direction (negative) for triceps femoris, rectus femoris, gluteus major and gluteus medialis. As for "Upright 90", it is a stage of fixing the backbone on horizontal level and vertical axis through isometric work for low back muscles and iliac muscle. These muscles help rotating and achieving stability and balance during sitting in addition to the work of external rotators (quadriceps - rectus femoris - vastuslateralis vastusmedialis). As for "Lean Forward $70^{\circ}$ ", it is a stage of eccentric contraction for adductor 
muscles, iliac muscles and tensor fasciae through eccentric work on counter direction of force (negative) for triceps femoris, rectus femoris, gluteus major and medials.

\section{Knee Joint:}

Joint extension begins through the leg on a sideway level and horizontal axis with concentric contraction for extensors. This is followed by motion of knee muscles through thigh with eccentric work for extensors (quadriceps - rectus femoris - vastuslateralis - vastusmedialis).

The researchers conclude that there are differences for all sitting positions in front of computer and this explains the short breath and shortness of anterior muscles.

Second: Results of EMG for Identifying Percentages of Contribution for some Major Muscles According to Its Role during Sitting:

As for "Lie Back 135", table (2) and figure (2) indicate that the highest percentage of involvement was for muscles of trunk backward movement including pectorals major and rectus abdomens (6\%), erector spinae (5\%), Latissimus dorsi (4\%) and sacrospinalis (3\%). Burnett et al (2008) (4) explained that sitting positions represent common cause of pain in cervical and lumbar spine. There are statistically significant differences among all sitting positions for chest muscles, low back muscles and neck muscles.

Rectus femoris has the least contribution (3\%) during maximum contraction, followed by semimembranosus $(2 \%)$ and finally gastrocnemius $(1.5 \%)$ to help the individual keep thigh angle in horizontal level. There are slight differences in thigh angle to affect muscle activity. Mabb et al (2013) (7)indicated that in "Lie Back 135" the trunk is leaned backward to keep balance through maintaining center of gravity behind thigh axis.

As for "Upright $90^{\circ}$ ", it is the least stage of all in contraction as contraction of pectorals major decreases $(4 \%)$. This is supported by erector spinae $(5 \%)$, rectus abdomens $(4 \%)$, latissimus dorsi (4\%) and sacrospinalis (1\%) through isometric work. This is in agreement with Burnett et al (2008) ((4) and Claus et al (2009) (6) in that changing the backbone angle between right and semi-right leads to changes in pressure of vertebrae from other positions with more than (50\%). This indicates changes in backbone positions.

As for "Lean Forward 70", here comes the greatest involvement of pectorals major and rectus abdomens $(8 \%)$ followed by latissimusdorsi $(6 \%)$, erector spinae $(2 \%)$ and sacrospinalis (3\%). Cramer et al (2011) (5) indicated that a marked increase in muscle activity was recorded for lumbar spine muscles during upright position of the spine compared with cervical spine and leaning backwards. The rip cage controls the movement of lumbar and cervical spine. This is in agreement with Samir Elgazar (2013) (10).

Rectus femoris shows highest involvement (3\%) during max contraction with semimembranosus (4\%) and gastrocnemius (1\%) for maintaining thigh angle.

Therefore, the researchers concluded percentages of contribution of some major muscles according to its roles in sitting positions as the position of Lie back $135^{\circ}$ is done through leaning backward with trunk to maintain balance through keeping center of gravity behind thigh axis.

Third: Designing the Recommended Compensatory Exercises Program 
Through results of anatomical analysis and EMG analysis, the researchers followed the following steps:

- Identifying anatomical and EMG criteria for the recommended exercises as follows:

- Choosing exercises for erector spinae due to its role supporting changes of pelvic joint

- Symmetry between extensors and flexors, especially in chest and back regions to maintain upright position

- Balance between lumbar and thigh muscles for their supportive role of trunk movement

- Maintaining the health of spine and learning healthy body biomechanics

- Stretching knee ligaments as they support pelvic movement

- Flexibility of thigh as it supports trunk

- Choosing all types of exercises (max power - speed strength - endurance) for upper body

- Using these principles for designing compensatory exercises

\section{The recommended exercises:}

Ex1: Standing with hands in front. Raise hands backward and left shoulders up till shoulder griddles come together. Maintain for seconds and return to beginning position

Ex2: Hands sideways on shoulder level and forearms up. Alternating trunk twist (lift/right) and pressing hands on same direction

Ex3: standing with hands sideways

1. Raise hands forward and upward, move right foot backward and lean backward with trunk

2. Lean with trunk forward and downward and clap both hands behind front leg

3. Stretch trunk upward and return legs to ready position. Repeat for the other leg.

\section{Ex4:}

1. Stand with hands beside you

2. Lean forward and tough the floor

3. Raise trunk and hands upward and lean backward

\section{Ex5:}

1. On your knees with hand clasped behind head

2. Rise trunk up and lean backward

3. Return to ready position

\section{Ex6:}

1. On your knees and hands beside you. Lift leg extended forward and sideward. Right leg flexed backward

2. Lean backward and open hand and push backward

3. Return to ready position and repeat with alternating legs

\section{Ex7:}


1. Lie on your back with hands beside you

2. Flex right leg and hold your knee. Push it to chest and maintain for 5-10 sec

3. Return to ready position and repeat for the other leg

\section{Ex8:}

1. Lie on your abdomen with hands forward

2. Left your trunk with head low and raise legs upwards. Maintain for 5-10 sec

\section{Ex9:}

1. Sit on your legs

2. Lean the trunk towards thighs and extends arms forward on floor maintain for $10-20 \mathrm{sec}$

\section{Conclusions:} following:

In the light of anatomical analysis and EMG analysis, the researchers concluded the

6- Descriptions of various sitting positions in front of computer are as follows:

- Muscle groups with highest contraction during Lie Back $135^{\circ}$ are: pectorals major - rectus abdomens - erector spinae - latissimus dorsi - deltoid

- Muscle groups with highest contraction during Upright $90^{\circ}$ are: rectus abdomens pectorals major - rectus femoris - erector spinae - latissimus dorsi

- Muscle groups with highest contraction during Lean Forward $70^{\circ}$ are: rectus abdomens pectorals major - rectus femoris - latissimus dorsi - deltoid

7- Descriptions of various sitting positions in front of computer according to EMG for contribution percentages are as follows

- Lie Back 135: highest contribution for trunk movers

- Upright 90: least percentage of contractions for all muscle groups

- Lean Forward 70: highest contribution for pectorals major - rectus abdomens

8- There is no best position for sitting as the body should not stay on one position for too long

9- Fixed positions cause negative effects on the spine and its working muscles

10- Compensatory exercises are designed

\section{Recommendations:}

In the light of these conclusions, the researchers recommend the following:

1- Applying the recommended compensatory exercises program

2- It is important to identify the mechanical aspects of sitting and serious risks and disorders resulting from incorrect sitting positions in addition to trying to maintain ideal position in front of computer

3- Increasing health awareness among youth and governmental employees who use computer to form healthy habits of sitting in front of computers

4- Using ergonomics applications to save work time and make work places safer and more effective

5- Using results of this research to guide further research works on the sports field 


\section{References:}

1- Ahmed Elgammal, BodaRosenhahn and ReinhardKiette (eds) Human Motion Understanding, Modeling, Capture and Animation. $2^{\text {nd }}$ Workshop, in conjunction with ICCV 2007

2- Briggs AM, Smith AJ, Straker LM, Bragge P. Thoracic spine pain in the general population: prevalence, incidence and associated factors in children, adolescents and adults. A systematic review. BMC Musculoskeletal Disorder 2009 Jun; 1077-89

3- Mohamed GaberBreka and KhiriaElsokary: Basic principles of biomechanics in sport: qualitative analysis. Part II, Munshaat Al-Maaref - Alexandria - Egypt 2010 (in Arabic)

4- Burnett A, O'Sullivan P, Ankarberg L, Gooding M, Nelis R, Offermann F, Lower lumbar spine axial rotation is reduced to a neutal spine posture. Man Ther 2008 Aug; 13300-306

5- Cramer SC; Sur M; Dobkin BH; O’Brien C; Sanger TD; Trojanowski JQ; Rumsey JM; L; (June 2011). "Harnessing neuroplasticity for clinical application". Brain : a journal of neurology 134(Pt6): 1591-609

6- Claus AP, Hides JA, Moseley GL, Hodges PW. Different was to balance the spine subtle changes in sagittal spinal curves affect regional muscle activity. Spine (2009)

7- Mabb Steven, Bettany-Saltikov J, Hodgson DA. Habitual perceived ideal and neutral sitting postures within an asymptomatic young adult population: muscle activity and sagittal spinal curvature. OA Musculoskeletal Medicine 2013 Aug 01:1(2):16

8- Matthew, Wyony: mcdn.com/sites/www.iadms.org/resource/resmgr/public/bul(2014)

9- Michelle Dawn: Muscles affected by sitting all day. Applied kinesiology (AK) is a technique in alternative medicine claimed to be able to diagnose illness 2013

10- http://www.samiralgazzar.c (20130

11- http://www.livestrong.com/article/507319-muscles-affected-by-sitting-allday/\#ixzz2hqikomob (2013)

12- http://www.livestrong.com/article/507319-muscles-affected-by-sitting-allday/\#ixzz2hqikomob back pain from sitting at a Des (2014)

13- http://www.breathing.com/articles/posture.htm (2014)

14- Article reviewed by Grygor Scott last updates on: Aug 16. (2013)

15- http://www.intechopen.com/books/biomechanics-application/applications-of-upper-limbbiomechanical-models-in-s (2006) 